\title{
The impact on health services utilization in a replication study of two self-management programmes for osteoarthritis of the knee and hip
}

Reinhard de Jong TNO Quality of Life, Leiden, The Netherlands and Netherlands School of Public \& Occupational Health, Amsterdam, The Netherlands, Erwin Tak TNO Quality of Life, Leiden, The Netherlands, Niek Klazinga University Medical Centre, Department of Social Medicine, University of Amsterdam, Amsterdam, The Netherlands and Municipal Health Services, Amsterdam, The Netherlands and Marijke Hopman-Rock TNO Quality of Life, Leiden, The Netherlands and Body@Work Research Centre Physical Activity, Work and Health TNO-VU University Medical Centre, Leiden/Amsterdam, The Netherlands

\begin{abstract}
Aim: As part of a replication study after the randomized controlled trial (RCTs) in the Netherlands, the impact was assessed on health services utilization and expenditure of two self-management programmes for older adults with osteoarthritis (OA) of the knee and hip. Background: Evidence-based patient education and exercise programmes, developed and tested in RCTs, are often insufficiently diffused among practitioners and primary healthcare providers and tend to have a modest reach in the population. Large-scale adoption in primary healthcare can be improved if programmes are feasible and effective in real life. Methods: The programmes were conducted in real-life conditions by primary healthcare providers (local health centres, home-care providers, physical therapy centres). Pre-test/post-test data were collected for consultation of the general practitioner (GP), medical specialist, physical therapist, and for the use of OA medication, as well as for the expenditure for physical therapy and OA medication. Findings: In total, 20 Knee and 20 Hip programmes were carried out by 18 providers. The Knee programmes were attended by 204 participants and the Hip programmes by 169 participants. Physical therapy and use of OA medication for both programmes and consultation of the medical specialist for the Hip programme decreased. No effect was observed for consultations of the GP. Expenditure for physical therapy and use of OA medication could not be assessed, due to difficulties to obtain sufficient reliable data from participating health insurers. Both programmes produced similar outcomes in real-life conditions compared to their RCTs. The implications are discussed as to accurate data collection on OA expenditure, future cost-utility and cost-effectiveness studies, and the large-scale implementation of the programmes in the Dutch primary healthcare system.
\end{abstract}

Key Words: health services utilization; implementation; osteoarthritis; self-management programme

Received: June 2006; accepted: August 2007

\section{Introduction}

Evidence-based patient education and exercise programmes, developed and tested in randomized controlled trials (RCTs), are often insufficiently diffused among practitioners and primary

Address for correspondence: Reinhard de Jong, Netherlands School of Public \& Occupational Health, P.O. Box 2557, 1000 CN Amsterdam, The Netherlands. Email: r.dejong@nspoh.nl healthcare providers and have a modest reach in the population (King et al., 1998; Nutbeam, 1998; Potvin, 1998; Prohaska, 2000). Large-scale adoption is improved if programmes are feasible and effective in real life (Øvretveit, 2000; Prohaska et al., 2000). One controlled trial is not a sufficient basis to warrant the large-scale adoption, and replication studies in different locations are needed to produce effective programmes. The outcomes of replication studies facilitate the decision

(C) 2008 Cambridge University Press 
Table 1 Characteristics of RCTs and replication studies

\begin{tabular}{|c|c|c|}
\hline Characteristics & $\mathrm{RCT}$ & Replication studies \\
\hline Research location & $\begin{array}{l}\text { Research \& Development institute } \\
\text { with research experts }\end{array}$ & Field organizations with practitioners \\
\hline Research purpose & $\begin{array}{l}\text { Focus on programme effectiveness } \\
\text { (effect evaluation) }\end{array}$ & $\begin{array}{l}\text { Focus on feasibility and effectiveness in } \\
\text { practice (process and effect evaluation) }\end{array}$ \\
\hline Research methodology & $\begin{array}{l}\text { Intervention and control groups with } \\
\text { pre- and post-test; emphasis on } \\
\text { quantitative methods and (advanced) } \\
\text { statistical analyses } \\
\text { Focus on internal validity }\end{array}$ & $\begin{array}{l}\text { Triangulation of research methods } \\
\text { (quantitative and qualitative); one single } \\
\text { group pre-test and post-test for measuring } \\
\text { effects } \\
\text { Focus on external validity }\end{array}$ \\
\hline $\begin{array}{l}\text { Recruitment of } \\
\text { programme participants }\end{array}$ & Usually one recruitment strategy & $\begin{array}{l}\text { Combined use of mass media and } \\
\text { (inter)personal recruitment strategies }\end{array}$ \\
\hline $\begin{array}{l}\text { Selection of programme } \\
\text { participants }\end{array}$ & $\begin{array}{l}\text { Strict application of inclusion and } \\
\text { exclusion criteria }\end{array}$ & $\begin{array}{l}\text { Degree of flexibility in inclusion and } \\
\text { exclusion criteria }\end{array}$ \\
\hline Programme delivery & $\begin{array}{l}\text { Strictly according to protocol or } \\
\text { guidelines }\end{array}$ & $\begin{array}{l}\text { Adaptation of programme or components to } \\
\text { provider's available facilities and resources }\end{array}$ \\
\hline $\begin{array}{l}\text { Collaboration with } \\
\text { stakeholders }\end{array}$ & Limited & $\begin{array}{l}\text { Extensive (national organizations of } \\
\text { providers, local and regional providers, } \\
\text { funding agencies) }\end{array}$ \\
\hline
\end{tabular}

$\mathrm{RCT}=$ randomized controlled trial.

of policy makers, funding agencies and (healthcare) providers to adopt programmes.

However, replication studies differ from RCTs and have implications for programme delivery, programme outcome and research design. In a replication study, researchers and providers have less control over programme delivery. Providers often have fewer resources, and more partners to co-operate and negotiate with than do investigators in a research study (Prohaska, 2000). They may need to re-design or adapt the contents and procedures of programmes for specific purposes and circumstances. The research focus of RCTs is to assess effectiveness in an effect evaluation, whereas replication studies are a combination of process and effect evaluation, using triangulation of methods (Tones, 1997). The characteristics of RCTs and replication studies are given in Table 1.

We describe, as part of a replication study, the assessment of the health services utilization and expenditure of two programmes for older adults with osteoarthritis (OA) of the knee and hip.

\section{Replication study of two OA programmes}

TNO Quality of Life in the Netherlands (an independent institute for applied research) developed and evaluated, in randomized controlled trials (RCTs) at the TNO premises, two health education and physical exercise programmes for older adults ( $>55$ years) with OA of the knee or the hip. Both programmes aim to maintain the quality of life of OA patients by reducing pain and stabilizing mobility. An additional aim of the Knee programme is to improve knowledge of OA and self-efficacy.

The RCT of the OA Knee programme showed after six months a positive effect on OA knowledge, pain and self-efficacy, and the OA Hip programme after three months was found to have a positive effect on pain and hip function (Hopman-Rock and Westhoff, 2000; Tak et al., 2005). No effects on the short term were found on mobility for both programmes.

Participants in the OA Knee programme trial made significantly fewer visits to physical therapists, whereas there was no change in visits to general practitioners (GPs) or in OA medication use. The RCT of the Hip programme did not measure OA knowledge, self-efficacy and health services utilization.

We decided to replicate the studies in real-life conditions and developed a replication study for both programmes with three objectives: (1) to assess the feasibility of the programmes in practice; (2) to determine the clinical and behavioural

Primary Health Care Research \& Development 2008; 9: 64-74 
outcomes of the programmes, when carried out in real-life conditions; and (3) to assess the impact on the health services utilization (physical therapy, consultation of GP and medical specialist, the use of OA medication), and the impact on healthcare expenditure.

Assessment of health services utilization of group-based self-management programmes for OA patients is in the Netherlands as yet unknown. We decided to include the assessment of health services utilization, because we assumed primary care providers and potential funding agencies, such as health insurance companies, to be interested in a comprehensive picture of the outcomes of the programmes in real-life conditions.

A process and effect evaluation was carried out. The process evaluation showed that both programmes were feasible in practice and could be carried out by the providers as intended (Jong De et al., 2003). The outcomes of the effectevaluation were comparable with the RCTs and indicated positive effects on OA knowledge and self-efficacy (Knee program) and on pain (both programmes) (Jong De et al., 2004). Here we report on the assessment of and the impact on the health services utilization and expenditure of both programmes.

\section{Materials and methods}

\section{OA programmes}

The OA Knee programme combines moderate physical exercises and extensive health education and consists of six weekly sessions of two hours (one hour with health education and one hour with physical exercises) with a maximum of 15 participants (Hopman-Rock and Westhoff, 2000). The OA Hip programme is a hip muscle strengthening training, using fitness equipment, combined with limited health education and with ergonomic advice at home. The duration is nine weekly sessions of one hour with a maximum of 12 participants. The first session is on health education, the remaining sessions are physical training sessions (Tak et al., 2005). The physical exercises of both programmes are supervised by certified physical therapists. The health education in the OA Knee programme (lifestyle and exercise, pain management, weight control and dieting) is interactively conducted by a peer educator and in the OA Hip programme by the physical therapist.

Participants of both programmes receive a course book, which includes a home-based exercise programme.

\section{Primary care providers and requirements for programme delivery}

We performed a replication study in collaboration with the national associations of three types of primary care providers, that is home-care organizations, physical therapy practices and local health centres, all of which were interested in adopting the programmes. The local branches of these providers met all necessary requirements as to qualified personnel, facilities and equipment. Regional home-care organizations provide longterm, home-based care to chronically ill, handicapped and elderly in need. They also deliver group-based prevention programmes, eg exercise programmes for elderly with chronic conditions. Physical therapy practices are embedded in the primary healthcare system and provide individual physical therapy for a large variety of conditions and for rehabilitation purposes. They gradually initiate group-based exercise and fitness programmes for different target groups, among which are the elderly. Local health centres are multidisciplinary centres and combine the primary healthcare functions of family medicine, social work, physical therapy and dental health.

We were able to involve four health insurance companies to participate financially. They perceived the programmes as innovative services for their insurants and also expressed a positive intention for future funding.

In conjunction with the health insurance companies and the providers, four pilot regions were selected, two urban and two semi-rural areas (Figure 1), to ensure sufficient insurants of the insurance companies to participate in the programmes.

We recruited 20 primary care providers (the maximum number within the available budget), each of which assigned a contact person who received verbal instructions and written guidelines for the local implementation of the programmes and manuals for programme delivery. Because fidelity and completeness of programme delivery are predictors of effectiveness (Rossi 


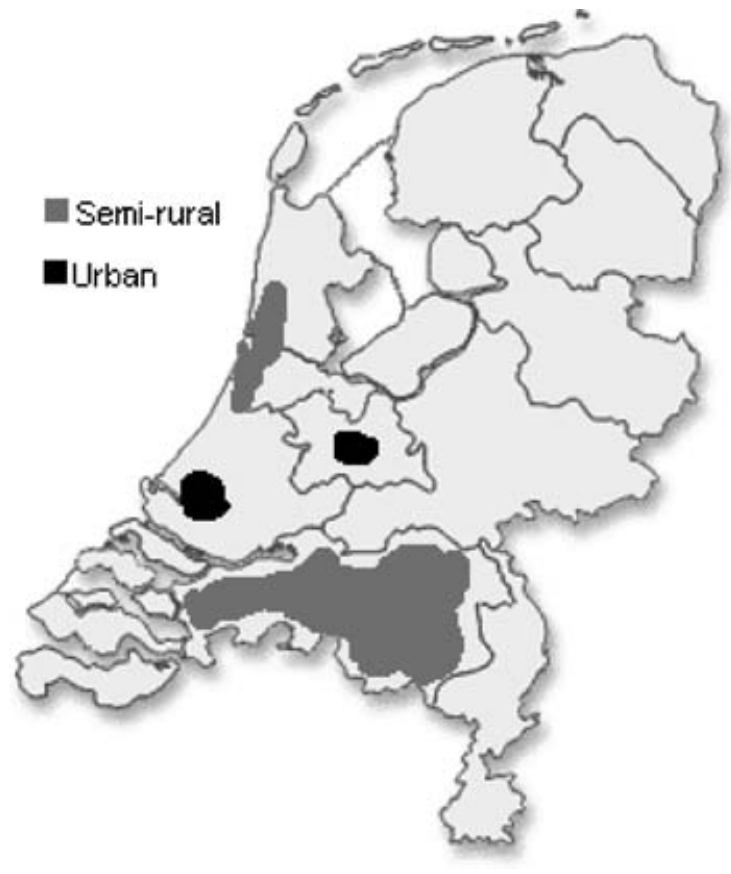

Figure 1 Implementation areas in the Netherlands

et al., 1999), both the implementation guidelines and the programme manuals contained instructions for programme planning and delivery. Providers could adjust the programme content and procedures, provided that they did not change the core components. To allow providers to introduce minor adaptations to a programme improves commitment to, and delivery of the core components of the programme (Rogers, 2003).

\section{Programme participants}

Programme participants were adults aged 55 years or older with symptomatic OA of the knee or hip. We instructed physical therapists at the providers in the use of an assessment protocol, including a decision tree (applied in the RCTs) to determine the eligibility of programme applicants. The protocol is based on the criteria of the American College of Rheumatology (ACR), which are also used by Dutch GPs (Altman et al., 1986; 1991).

All applicants whose OA of the knee or hip was diagnosed by a GP were included. Applicants with self-reported OA of the hip were only included if they reported pain at endorotation of the hip and morning stiffness. Applicants with self-reported OA of the knee were included if they reported crepitation, swelling and stiffness of one or both knee joints. Excluded from participation were applicants on a waiting list for knee or hip replacement and/or with self-reported severe mobility problems.

\section{Outcome measures}

Outcome measures for both programmes were proportion of participants who consulted their GP, physical therapist or medical specialist (orthopaedic specialist and/or rheumatologist); frequency of visits to these health professionals; use of medication for OA (NSAIDs and painkillers, prescribed by the GP); and the related expenditure for $\mathrm{OA}$ medication and physical therapy.

\section{Design}

The nature of the study was pragmatic. We were interested in the outcomes of the programmes in real-life conditions after the RCTs. Therefore, we considered a pre-test/post-test design to be sufficient for assessing the impact on the health services utilization and the related expenditure.

\section{Data collection}

All participants completed questionnaires before and after programme delivery. The budget of the project did not allow follow-up measurements. Data were collected using single questions from the RCT questionnaire of the Knee programme: participants were asked how often they had visited health professionals (GP, physical therapist, rheumatologist, orthopaedic specialist) in the past two months at pre-test (both programmes) and in the past six weeks at post-test of the Knee programme, and in the past two months at post-test of the Hip programme (the two programmes lasted six weeks and two months, respectively). Consultations of the physical therapists who conducted the programmes were excluded.

As to use of OA medication, we asked at pretest whether over the last 12 months medication was used for OA symptoms and at post-test during the past month.

Primary Health Care Research \& Development 2008; 9: 64-74 
We arranged with the health insurance companies to provide data about the expenditure on OA medication and physical therapy of the programme participants, holding an insurance policy. Specific regulations in the Dutch health insurance system do not allow companies to provide expenditure data on consultations of the GP and medical specialist. Before participation, participants provided their written informed consent to the use of their records held by their health insurance company for research purposes. The companies sent to TNO an overview of expenditure for OA medication and physical therapy per insured participant over the year before and over the year after the intervention. This time period was chosen to collect substantial data over a longer period. The overview of physical therapy expenditure for OA of knee or hip was based on a diagnostic code system for paramedic treatment, used by all Dutch health insurers. The overview of expenditure for OA medication was based on expenditure for NSAIDs.

\section{Statistical analyses}

To test for differences in the background variables of participants in the RCTs and the replication study in order to determine the validity of the replication study, we used the $t$-test for means of two groups and the $\chi^{2}$ test for nominal variables. As to the outcome measures, we used paired $t$-tests to test for differences between pretest and post-test scores (two-sided) and the $\chi^{2}$ tests for nominal variables. The mean frequency of consultations of the health professionals per week was calculated, to adjust for differences in the pre- and post-test evaluation period. $\chi^{2}$ tests were used to test for differences in self-reported use of OA medication. For all analyses, we used a significance level of $\alpha<0.05$.

\section{Results}

\section{Programmes and programme participants}

In total, 20 Knee and 20 Hip programmes were carried out by 18 primary care providers. Of the 20 recruited providers, two decided to withdraw at the start of the study. All providers delivered the core components of the programmes according to the guidelines.

Primary Health Care Research \& Development 2008; 9: 64-74
The Knee programmes were attended by 204 participants and the Hip programmes by 169 participants. Questionnaires were completed by 177 participants $(87 \%)$ of the Knee programme and by 153 participants (91\%) of the Hip programme. In the Knee programme, 20 people and in the Hip programme 21 people did not meet the age ( $>55$ years) and attendance criteria ( 4 out of 6 sessions of the Knee programme and six out of nine sessions of the Hip programme). The data of 157 participants $(77 \%)$ of the Knee programme and of $132(78 \%)$ of the Hip programme (a total of 289) were included in the analysis of the selfreported health services utilization.

Regarding the healthcare expenditure analysis, 207 participants ( $72 \%$ of the participants included in the analysis) had an insurance policy with one of the four co-financing health insurance companies. However, four patients were covered by one particular health insurance company, which decided not to provide data from the patient records. Two health insurance companies provided separate overviews for the participants of the Knee or the Hip programme, and the third company could only provide a combined overview of expenditure for physical therapy of both programmes, but not for OA medication. Fifty-three records were made available for Knee programme participants, 41 for Hip programme participants, and 39 for Hip/Knee programme participants, in total 133 patient records.

\section{Background variables of programme participants}

The characteristics of both groups in the replication study are shown in Table 2 , in combination with the characteristics of programme participants in the RCTs.

The participants of the Knee programme were significantly older in the replication study than in the RCT $(t=3.98, P=0.00)$, unlike the participants of the Hip programme $(t=0.92, P=0.36)$. The number of chronic conditions was significantly higher in the replication study than in the RCTs in both the Knee programme $(t=5.67$, $P=0.00)$ and in the Hip programme $(t=2.83$, $P=0.00)$. Level of income of the Knee programme participants was overall significantly higher in the replication study $\left(\chi^{2}=7.41, P=0.02\right)$ than in the RCT; it was not measured for the Hip 
Table 2 Characteristics of participants in Knee and Hip programme in the RCTs and in the replication study

\begin{tabular}{|c|c|c|c|c|}
\hline & \multicolumn{2}{|c|}{ Knee programme } & \multicolumn{2}{|c|}{ Hip programme } \\
\hline & RCT & Replication study & RCT & Replication study \\
\hline Number of participants & 56 & 157 & 45 & 132 \\
\hline Age (years); mean (SD) & $65(5.3)$ & $69(7.3)^{*}$ & $67(7.6)$ & $66(7.5)$ \\
\hline Sex/women (\%) & 78 & 71 & 64 & 70 \\
\hline \multicolumn{5}{|l|}{ Civil status (\%) } \\
\hline Married/living together & 70 & 59 & 62 & 64 \\
\hline Divorced/widow(er)/single & 30 & 41 & 38 & 36 \\
\hline \multicolumn{5}{|l|}{ Education } \\
\hline Primary & 17 & 11 & 21 & 10 \\
\hline Secondary & 56 & 68 & 62 & 52 \\
\hline Higher (university, college) & 27 & 21 & 17 & 38 \\
\hline \multicolumn{5}{|l|}{ Income $(\%)^{a}$} \\
\hline Low & 39 & $17^{*}$ & & 21 \\
\hline Average & 22 & $42^{*}$ & & 42 \\
\hline High & 39 & $21^{*}$ & & 26 \\
\hline Number of chronic conditions; mean (SD) & $2.2(1.5)$ & $3.4(1.9)^{*}$ & $2.6(1.9)$ & $3.7(2.3)^{*}$ \\
\hline
\end{tabular}

${ }^{*} P<0.05$.

a Percentages in replication study do not add up to $100 \%$.

$\mathrm{RCT}=$ randomized controlled trial.

programme. Participant level of education did not differ in the Knee programme $\left(\chi^{2}=3.84, P=0.15\right)$, but was significantly higher in the Hip programme in the replication study $\left(\chi^{2}=2.83, P=0.00\right)$. Sex and civil status of the participants in both programmes did not differ significantly.

\section{Outcome measures}

After programme completion, significantly fewer patients reported being treated by a healthcare professional (Table 3). This decrease was statistically significant for physical therapy in the Knee programme. Only in the Hip programme, the selfreported frequency of visits to a physical therapist or medical specialist decreased significantly (Table 4).

Self-reported OA medication use after completion of either programme significantly decreased for the Knee programme $\left(\chi^{2}=41.9\right.$, $P=0.00)$ and for the Hip programme $\left(\chi^{2}=28.4\right.$, $P=0.00)$.

The outcomes for either programme as to the expenditure for physical therapy and OA medication, measured by the health insurance companies, vary from decrease to increase of expenditure, with large individual variations in costs (Table 5). Health insurer II reported for both programmes reductions in expenditure for physical therapy and OA medication (all reductions more than $25 \%$ ). Health insurer I reported a small reduction in physical therapy expenditure only for the Knee programme and a small increase in expenditure for OA medication for both programmes. Health insurer III reported a $15 \%$ increase in the combined expenditure for physical therapy of both programmes.

\section{Discussion}

This study assessed the health services utilization and expenditure of two health education and physical exercise programmes for older adults with OA of the knee and hip, delivered in real-life conditions.

\section{Background variables of programme participants}

The profile of the participants in the replication study shows similarities with the profile in the Primary Health Care Research \& Development 2008; 9: 64-74 
Table 3 Number of participants under OA treatment of Knee programme $(n=157)$ and Hip programme $(n=132)$

\begin{tabular}{|c|c|c|c|c|c|c|}
\hline & \multicolumn{2}{|c|}{ Knee programme } & \multirow{2}{*}{$\begin{array}{l}t \text {-Test results } \\
\text { (two-sided) }\end{array}$} & \multicolumn{2}{|c|}{ Hip programme } & \multirow{2}{*}{$\begin{array}{l}t \text {-Test results } \\
\text { (two-sided }\end{array}$} \\
\hline & Pre-test & Post-test & & Pre-test & Post-test & \\
\hline No treatment & $82(52 \%)$ & $104(66 \%)$ & $t=-3.51, P=0.00^{*}$ & 59 (45\%) & $66(50 \%)$ & $t=1.26, P=0.21$ \\
\hline Physical therapist & $33(21 \%)$ & $17(11 \%)$ & $t=3.37, P=0.00^{*}$ & $38(29 \%)$ & $30(23 \%)$ & $t=1.80, P=0.07$ \\
\hline General practitioner & $33(21 \%)$ & $28(18 \%)$ & $t=0.93, P=0.35$ & $37(28 \%)$ & $29(22 \%)$ & $t=1.47, P=0.14$ \\
\hline Medical specialist & $26(17 \%)$ & $24(15 \%)$ & $t=0.47, P=0.64$ & $24(18 \%)$ & $22(17 \%)$ & $t=0.63, P=0.53$ \\
\hline Other & $5(3 \%)$ & $6(4 \%)$ & $t=0.38, P=0.71$ & $10(8 \%)$ & $8(6 \%)$ & $t=0.82, P=0.42$ \\
\hline
\end{tabular}

${ }^{*} P=<0.05$.

$\mathrm{OA}=$ osteoarthritis.

Table 4 Frequency visits to health professionals of Knee programme $(n=157)$ and Hip programme ( $n=132)$ participants

\begin{tabular}{|c|c|c|c|c|c|c|c|c|}
\hline & \multicolumn{4}{|c|}{ Knee programme } & \multicolumn{4}{|c|}{ Hip programme ${ }^{b}$} \\
\hline & $n$ & $\begin{array}{l}\text { Pre-test; } \\
\text { mean (SD) }\end{array}$ & $\begin{array}{l}\text { Post-test; } \\
\text { mean (SD) }\end{array}$ & $\begin{array}{l}t \text {-Test results } \\
\text { (two-sided) }\end{array}$ & $n$ & $\begin{array}{l}\text { Pre-test; } \\
\text { mean (SD) }\end{array}$ & $\begin{array}{l}\text { Post-test; } \\
\text { mean (SD) }\end{array}$ & $\begin{array}{l}t \text {-Test results } \\
\text { (two-sided) }\end{array}$ \\
\hline $\begin{array}{l}\text { Physical } \\
\text { therapist }\end{array}$ & 36 & $0.66(0.67)$ & $0.58(0.75)$ & $\begin{array}{l}t=0.80 \\
P=0.43\end{array}$ & 43 & $0.65(0.59)$ & $0.38(0.49)$ & $\begin{array}{l}t=2.84 \\
P=0.00^{*}\end{array}$ \\
\hline $\begin{array}{l}\text { General } \\
\text { practitioner }\end{array}$ & 41 & $0.16(0.22)$ & $0.10(0.14)$ & $\begin{array}{l}t=1.03 \\
P=0.11\end{array}$ & 42 & $0.13(0.13)$ & $0.10<0.12$ & $\begin{array}{l}t=1.20 \\
P=0.24\end{array}$ \\
\hline $\begin{array}{l}\text { Medical } \\
\text { specialist }\end{array}$ & 31 & $0.11(0.12)$ & $0.10(0.14)$ & $\begin{array}{l}t=0.35 \\
P=0.73\end{array}$ & 35 & $0.11(0.16)$ & $0.05(0.08)$ & $\begin{array}{l}t=2.20 \\
P=0.03^{*}\end{array}$ \\
\hline
\end{tabular}

${ }^{*} P=0.05$.

${ }^{a}$ Mean number of visits per week over two months at pre-test and at post-test per week over six weeks (duration of the programme).

${ }^{\mathrm{b}}$ Mean number of visits per week over two months at pre-test and at post-test per week over eight weeks (duration of the programme).

RCTs. In the replication study, however, participants had significantly more chronic conditions than did participants in the RCTs and the participants in the Knee programme were significantly older. This reflects the enrolment strategy. Most participants had applied to join the programmes through announcements in the regional periodicals of the home-care organizations. Most people using home-care are elderly and, thus, are expected to have more chronic conditions. This may have an impact on the use of medication and on the pattern of consultation of health professionals.

\section{Consultation of health professionals and use of $\mathrm{OA}$ medication}

Both programmes had an impact on physical therapy, but in the replication study of the Knee programme, a decrease in the number of Primary Health Care Research \& Development 2008; 9: 64-74 participants using physical therapy was found, and not a decrease in the frequency of consultations, as was observed in its RCT. The decrease in physical therapy can be related to the selfreported increase in self-efficacy of the programme participants as was observed in both RCTs and in the effect evaluation of the replication study (Hopman-Rock and Westhoff, 2000; Jong De et al., 2004; Tak et al., 2005). Increased self-efficacy (as measured by scales from the questionnaire by Lorig et al., 1989) indicates increased coping abilities, regarding OA symptoms.

Decrease in physical therapy might also have occurred, because participants adhered to the regularly given advice from the physical therapists who conducted the programmes, to stay actively involved in physical exercise and to follow-up the home-based exercise programme on a daily basis in order to reduce OA symptoms. 
Table 5 Expenditure ${ }^{a}$ for physical therapy and OA medication (mean (SD) per health insurance company in Euros for Knee and Hip programme and combined programmes

\begin{tabular}{|c|c|c|c|c|}
\hline & \multicolumn{2}{|l|}{ Physical therapy } & \multicolumn{2}{|l|}{ OA medication } \\
\hline & Pre-test mean (SD) & Post-test mean (SD) & Pre-test mean (SD) & Post-test mean (SD) \\
\hline \multicolumn{5}{|c|}{ Expenditure for Knee programme } \\
\hline Health Insurer I $(n=35)$ & $143.5(251.6)$ & $135.3(249.6)$ & $64.7(56.8)$ & $67.0(49.7)$ \\
\hline Health Insurer II $(n=18)$ & $108.3(182.3)$ & $32.9(66.4)$ & $57.5(138.3)$ & $50.4(88.3)$ \\
\hline \multicolumn{5}{|c|}{ Expenditure for Hip programme } \\
\hline Health Insurer I $(n=20)$ & $142.3(180.0)$ & $144.1(268.2)$ & $133.8(144.2)$ & $143.6(137.7)$ \\
\hline Health Insurer II $(n=21)$ & $128.4(142.6)$ & $97.5(172.0)$ & $33.5(57.3)$ & $14.5(28.7)$ \\
\hline \multicolumn{5}{|c|}{ Combined expenditure for Knee and Hip programme } \\
\hline Health insurer III $(n=39)$ & $278.8(270.3)$ & $311.1(497.1)$ & & \\
\hline
\end{tabular}

${ }^{\text {a }}$ Average expenditure for physical therapy and OA medication, measured over 12 months before the programme and over 12 months after the programme.

$\mathrm{OA}=$ osteoarthritis.

Neither programme significantly affected the consultation of GPs. This is in line with the outcome of the RCT of the Knee programme. Due to the relative short duration of the programmes, in combination with a relative low frequency of visits to a GP, reduction in GP consultations during programme delivery is unlikely. In addition, both RCTs and replication study showed that participants suffer from other chronic conditions. This implicates consultation of GPs during programme delivery other than for OA reasons.

The significant self-reported reduction in the frequency of visits to the medical specialist of participants of the Hip programme is perhaps due to the fact that at the time of the programme delivery a number of participants had no routine appointment with their medical specialist. Frequency of consultations of the medical specialist is usually much lower than consultations of the physical therapist and the GP.

In both programmes the use of $\mathrm{OA}$ medication decreased significantly. For the Knee programme, the decrease in OA medication use was consistent with the reduction in pain found in our effect study. Pain is a predictor for the use of painkillers, and thus an improved pain control among the participants in the Knee programme may have contributed to an increased control of the use of painkillers.

The combined self-reported reduction in physical therapy and in OA medication use indicates an improved control of OA symptoms, that is an increased self-efficacy (OA self-management abilities). This is consistent with the increased self-efficacy found in our evaluation of behavioural and clinical outcomes.

\section{Healthcare expenditure}

Despite a decrease in expenditure of Health Insurer II for both programmes and OA medication, the data from the health insurance companies on expenditure for physical therapy and OA medication indicate otherwise ambiguity, reflected in large individual variations in expenditure. They are inconclusive and reflect also the difficulties of obtaining reliable data from health insurance companies. When analysing the overviews of expenditure for physical therapy, we found several inconsistencies. Two health insurers referred in their overviews for each programme participant to a diagnostic code for physical therapy for OA. However, for several programme participants, the code could not be related to OA of knee or hip treatment, and in several cases no code at all was applied. In some individual cases, two to five codes, suggesting treatment for OA of knee or hip, were stated with related expenditure, of which one or more could not be related to OA of knee or hip. One health insurer had not been referred to the diagnostic codes at all. Given the inconsistencies in the data of the other two insurers, it is doubtful whether the data of the third insurer would be more reliable.

The replication study suggests that for obtaining reliable data about the health services utilization for OA, a guideline should be developed

Primary Health Care Research \& Development 2008; 9: 64-74 
in conjunction with the health insurance companies and the organizations of health professionals, involved in the treatment of OA patients.

\section{Comparison with the Arthritis Self- Management Programme (ASMP)}

The OA Knee programme is partly based on the ASMP (Lorig et al., 1993). Research on healthcare utilization and expenditure of the ASMP indicates variations in outcomes. A 4-year follow-up study and a cost-effectiveness study of the ASMP in the USA showed a $40 \%$ reduction in visits to physicians and significant cost savings over time (Lorig et al., 1993; Kruger et al., 1998). Follow-up studies (four and 12 months) in the UK of the ASMP, however, did not indicate significant changes in visits to GPs, but did indicate a significant reduction in visits to other health professionals (Barlow et al., 1997a; 1998; 1999; 2000). A 5-year follow-up study of a modified ASMP in Australia showed improved ability to cope with OA, but also significantly more contact with rheumatologists, physical therapists and occupational therapists (Lindroth et al., 1995).

Variations in outcomes are probably due to the differences in the healthcare systems, in the UK free at the point of delivery, as well as in the Netherlands. Reduction in consultations of the GP is therefore not likely to occur. The Australian example shows that participation in the ASMP can make participants more aware of the possibilities for OA treatment but has implications for higher healthcare costs.

\section{Limitations of the study}

The intended 'real-life conditions' of programme delivery was somewhat artificial, because the participants were still subjected to a research context, which may have influenced their selfreported response. We tried to minimize the spurious elements as much as possible. We had no contact with the programme participants ourselves. Contact with the primary care providers was also minimal.

The self-reported reductions in health services utilization must be interpreted with caution.

We measured consultations of GP, physical therapist and medical specialist and use of OA medication at post-test after programme Primary Health Care Research \& Development 2008; 9: 64-74 completion, whereas at pre-test we measured respectively over two months before the programme (health professionals) and 12 months (OA medication). The outcomes of the replication study of the Knee programme are, however, consistent with the outcomes of its RCT. For the Hip programme such a conclusion cannot be drawn, since health services utilization was not measured in the RCT. Ecological validity of the Knee programme may be considered (the ability of a programme, tested in controlled conditions, to produce comparable outcomes in real-life conditions).

\section{Implications}

Because the population is ageing, OA is expected to become a major public health problem, affecting the future use of healthcare resources. There is no cure for OA, and the aim of treatment is to control the symptoms with medication, physical therapy, exercise therapy and health education (Hopman-Rock and Westhoff, 2000). In the Netherlands, the prevalence of OA of the knee and hip among people older than 55 years is $20 \%$ for men and $33 \%$ for women (Chorus, 2000). The cost of treatment for OA is considerable: in 1999 it was estimated at $€ 1976$ million, accounting for $15 \%$ of the total expenditure for all locomotor conditions, which in turn accounted for $5.5 \%$ of all healthcare costs (Takken et al., 2002).

Predictors of healthcare utilization by OA patients are the prior use of health services and the chronicity of the pain symptoms (HopmanRock et al., 1997). Once patients with pain symptoms in the hip and/or knee have passed the 'threshold' of the GP, almost $40 \%$ of them consult their GP regularly. After referral by the GP, more than $30 \%$ receive physical therapy or are treated by an orthopaedic specialist or a rheumatologist. Approximately $30 \%$ are prescribed medication (Hopman-Rock et al., 1997).

Experiences with the Dutch programmes and with the ASMP in the US and the UK indicate that a large number of patients with $\mathrm{OA}$ are interested in self-management programmes. The main purpose of the programmes is to maintain quality of life and to improve physical activity, and the programmes should be considered as an adjunct to conventional (para)medical therapy for OA and not as a replacement. 
In the Netherlands, the introduction of a marketoriented healthcare system, in combination with governmental cuts in healthcare expenditure, stimulates new challenges for primary health care, such as for physical therapy practices. Insured physical therapy for example has been drastically restricted and practices are seeking alternative services. Group-based physical exercise therapy and health education may be such an alternative. Within a competitive health insurance market, health insurance companies gradually include self-management and prevention programmes in the insurance coverage as innovative services for their insurants.

Within this context, the primary health care providers in our study concluded that the overall results of these programmes regarding feasibility, clinical and behavioural outcomes and the impact on health services utilization warranted the inclusion of these programmes in the healthcare services they provide.

One co-financing health insurance company considered the results to be too ambiguous with respect to expenditure for physical therapy and OA medication, but acknowledged that both programmes were relevant interventions to be delivered within the healthcare system. Three health insurance companies considered the overall results to justify inclusion of programme participation in the coverage provided by their insurance policies and also considered reimbursement for primary care providers.

A cost-utility and cost-effectiveness analysis, once large-scale implementation is under way, are recommended, which reinforces the necessity of a guideline for a more accurate registration of $\mathrm{OA}$ health services utilization and expenditure.

\section{Acknowledgments}

The research was supported by grants to TNO Quality of Life from ZonMw/Netherlands Organization for Health Research and Development, Province of Noord-Brabant, Dutch Arthritis Association, Health Insurance Companies: Zilveren Kruis/Achmea, CZ Group, VGZ and OZ.

\section{References}

Altman, R., Asch, E., Bloch, D., Bole, G., Borenstein, D., Brandt, K., Christy, W., Cooke, T.D., Greenwald,
R. and Hochberg, M. 1986: Development of criteria for the classification and reporting of osteoarthritis. Classification of osteoarthritis of the knee. Arthritis \& Rheumatism 29, 1039-049.

Altman, R., Alarcon, G., Appelrouth, D., Bloch, D., Borenstein, D., Brandt, K., Brown, C., Cooke, T.D., Daniel, W. and Feldman, D. 1991: The American College of Rheumatology criteria for the classification and reporting of osteoarthritis of the hip. Arthritis \& Rheumatism 34, 505-14.

Barlow, J.H., Williams, B. and Wright, C.C. 1997a: Improving arthritis self-management among older adults: 'Just what the doctor didn't order'. British Journal of Health Psychology 2, 175-86.

Barlow, J.H., Turner, A.P. and Wright, C.C. 1998: Long-term outcomes of an arthritis self-management programme. British Journal of Rheumatology 37, 1315-319.

Barlow, J.H., Williams, B. and Wright, C.C. 1999: 'Instilling the strength to fight the pain and get on with life': learning to become an arthritis self-manager through an adult education program. Health Education Research 4, 533-44.

Barlow, J.H., Turner, A.P. and Wright, C.C. 2000: A randomised controlled study of the arthritis self management programme in the UK. Health Education Research 6, 665-80.

Chorus, A.J.M. 2000: Reuma in Nederland. De cijfers. Actualisering 2000 (Rheumatism in the Netherlands. Figures in 2000). TNO Prevention and Health, Leiden, the Netherlands.

Hopman-Rock, M., De Bock, G.H., Bijlsma, J.W.J., Springer, M.P., Hofman, A. and Kraaimaat, F.W. 1997: The pattern of healthcare utilization of elderly people with arthritic pain in the hip or knee. International Journal of Quality in Healthcare 9, 129-37.

Hopman-Rock, M. and Westhoff, M.H. 2000: The effects of a health educational and exercise programme for older adults with osteoarthritis of the hip or knee. Journal of Rheumatology 27, 1947-954.

Jong De, O.R.W., Hopman-Rock, M. and Klazinga, N.S. 2003: Interactief implementeren: een praktijkvoorbeeld van preventieprogramma's voor ouderen met artrose van de knie en heup. (Interactive implementation: a case study of self-management programmes for older adults with osteoarthritis of knee and hip). Tijdschrift voor Sociale Gezondheidszorg (Journal of Public Health) 4, 288-92.

Jong De, O.R.W., Hopman-Rock, M., Tak, E.C.P.M. and Klazinga, N.S. 2004: An implementation study of two evidence-based exercise and health education programmes for older adults with osteoarthritis of the knee and hip. Health Education Research 3, 316-25.

King, L., Hawe, P. and Wise, M. 1998: Making dissemination a two-way process. Health Promotion International 3, 237-44.

Kruger, J.M.S., Helmick, C.G., Callahan, L.F. and Haddix, A.C. 1998: Cost-effectiveness of the arthritis self-help course. Archives Internal Medicine 158, 1245-249.

Primary Health Care Research \& Development 2008; 9: 64-74 
Lindroth, Y., Bauman, A., Brooks, P.M. and Priestly, D. 1995: A 5-year follow-up of a controlled trial of an arthritis education programme. British Journal of Rheumatology 34, 647-52.

Lorig, K., Chastain, R.L., Ung, E., Shoor, S. and Holman, H.R. 1989: Development and evaluation of a scale to measure perceived self-efficacy in people with arthritis. Arthritis and Rheumatism 32, 37-44.

Lorig, K.R., Mazonson, P.D. and Holman, H.R. 1993: Evidence suggesting that health education for selfmanagement in patients with chronic arthritis has sustained health benefits while reducing healthcare costs. Arthritis \& Rheumatism 36, 439-46.

Nutbeam, D. 1998: Improving the fit between research and practice in health promotion: overcoming structural barriers. Canadian Journal of Public Health 6, (Suppl. 2), 18-23.

Øvretveit, J. 2000: Evaluating health interventions. United Kingdom: Open University Press.

Potvin, L. 1998: Methodological challenges in evaluation of dissemination programs. Canadian Journal of Public Health 6, (Suppl. 2), 79-83.
Prohaska, T.R., Peters, K.E., Warren, J.S. 2000: Health behavior: from research to community practice. In Albrecht, G., Fitzpatrick, R. and Scrimshaw, S., editors, Handbook of Social Studies in Health and Medicine. Thousand Oaks, CA: Sage.

Rogers, E.M. 2003: Diffusion of innovations, fifth edition. New York: The Free Press.

Rossi, P.H., Freeman, H.E. and Lipsey, M.W. 1999: Evaluation: a systematic approach, sixth edition. Newbury Park, CA: SAGE Publications.

Tak, E., Staats, P., Hespen van, A. and Hopman-Rock, M. 2005: The effects of an exercise programme for older adults with osteoarthritis of the hip. Journal of Rheumatology 32, 1106-113.

Takken, J., Polder, J.J., Meerding, W.J., Kommer, G.J. and Stokx, L.J. 2002: The costs of illness in the Netherlands. Bilthoven: RIVM.

Tones Keith, A. 1997: Beyond the randomised controlled trial. A case for 'judicial review' (Editorial). Health Education Research 12, i-iv. 